Original Research Article

\title{
Anti inflammatory effect of rhizome of Curcuma longa. Linn, in Albino rats by the method of Carrageenin induced paw oedema
}

\author{
Jayan Pariyani Savaringal, Lally M. S.*
}

Department of Pharmacology, Govt. Medical College, Thrissur, Kerala, India

Received: 30 December 2017 Accepted: 08 January 2018

\section{*Correspondence to:}

Dr. Lally M. S.,

Email: drlallymadhu@ gmail.com

Copyright: (C) the author(s), publisher and licensee Medip Academy. This is an openaccess article distributed under the terms of the Creative Commons Attribution NonCommercial License, which permits unrestricted noncommercial use, distribution, and reproduction in any medium, provided the original work is properly cited.

\begin{abstract}
Background: Curcuma longa or turmeric is a popular Ayurvedic herb, traditionally used for various inflammatory conditions including rheumatoid arthritis and spondylitis. Turmeric which containing phytochemical ingredient curcumin is used in India for centuries as a topical anti inflammatory agent. Many of the currently used anti inflammatory agents like NSAID's and glucocorticoids have many undesirable adverse effects, especially when they are used for long period. In the present study, Curcuma longa, a plant belonging to the Zingiberaceae family was chosen for investigating its anti-inflammatory effects. Methods: The rhizomes of Curcuma longa were collected locally. The extract was prepared by soxlet extraction with $50 \%$ ethanol. Albino rats of Wistar strain (170-250grams) obtained from the animal house of medical college Thiruvananthapuram were used. Aspirin was purchased from sigma Labs, Mumbai. Anti-inflammatory effect of the extract was done in rats by the method of Carrageenin induced paw oedema.

Results: The ethanolic extract of Curcuma longa inhibited the development of oedema at the end of 3 hours. The anti-inflammatory activity exhibited by the extract was dose dependent and statistically significant at dose levels of 1000$\mathrm{mg} / \mathrm{kg}$ and comparable to that of standard drug used Aspirin.

Conclusions: The present study with extract of Curcuma longa revealed that it has significant anti-inflammatory activity.
\end{abstract}

Keywords: Aspirin, Anti-inflammatory effect, Curcuma longa, Carrageenin induced paw oedema

\section{INTRODUCTION}

Turmeric (Curcuma longa) is a rhizomatous herbaceous perennial plant of the ginger family Zingiberaceae. Turmeric has been used in India for thousands of years and a major part of Ayurvedic medicine. It was first used as a dye and later for its medicinal properties. Turmeric is one of the key ingredients in many Indian dishes. It is considered auspicious in all religious observations in Indian households. It is a normal constituent of condiments and curry powders. In Ayurvedic practices turmeric has been used for the treatment for a variety of internal disorders, such as indigestion, throat infection, common cold, or liver ailments as well as topically to cleanse wounds or treat skin infections. In the present study, Curcuma longa, was chosen for investigating its antiinflammatory actions.

While studying the effects on acute inflammation, Ghatak and Basu reported high anti-inflammatory activity of intraperitoneal curcumin as well as of sodium curcuminate in the acute carrageenin-induced rat paw oedema, comparable with that of hydrocortisone. ${ }^{1}$ Curcumin the active ingredient in Curcuma longa, inhibit a number of different molecules involved in inflammation including phospholipase inducible tumour necrosis factors 
(TNF),cyclooxygenase, leukotrienes, thromboxane, collagenase and elastase. ${ }^{2}$

\section{Pathophysiology of inflammation ${ }^{3}$}

For centuries humans have intuitively identified inflammation with fire, undoubtedly as a result of the experience of redness, heat and pain associated with its occurrence. Acute response- include transudate, a movement of fluid of low protein content, containing predominantly albumin, from the intravascular to the extra vascular space. Exudative stage is followed by the influx of polymorphonuclear neutrophilic leukocytes. At this stage there is simultaneous recruitment of neutrophils and mononuclear cells as well as an ongoing repair reaction.

Chronic responses include macrophage response, plasma cell and lymphocyte rich response followed by granulomatous response. Macrophage appears during the late stage of inflammation called chronic inflammatory response. Humoral and cellular participants of inflammation include humoral elements like coagulation and fibrinolytic factors, kinins complement factors and immunoglobulin. Blood borne cells like polymorphonuclear leukocytes, monocytes, mononuclear phagocytes lymphocytes, eosinophils, basophils, mast cells and platelets also play important role in the process of inflammation.

\section{Chemical mediators of acute inflammation $^{3,4}$}

The arachidonic acid (AA) metabolites are the best-studied lipid mediators and virtually all cells involved in the inflammatory response have the capacity to generate at least some form of AA derivative. The free AA can be metabolized by two major enzymatic pathways, cyclooxygenase or lipoxygenase. The major cyclooxygenase products include prostaglandins (PGE2, PGF2 $\alpha$ and PGD2) contribute significantly to produce inflammation. The major lipioxygenase product includes leukotriens (LTB4, LTC4, LTD4, and LTE4) and hydroxyeicosatetraenoic acid (HETEs).

In mammalian cells two pathways of arachidonic acid metabolism namely cyclooxygenase pathway and lipooxygenase pathway are responsible for products of mediators of inflammation. Cyclooxygenase (COX) exists in two forms COX 1 and COX 2. COX 2 is induced in inflammatory cells by an inflammatory stimulus. It is responsible for production of mediators of inflammation. ${ }^{5}$ Chronic inflammation is characterized by infiltration with mononuclear cells including macrophage, lymphocytes and plasma cells. Non Steroidal anti-inflammatory drugs (NSAIDS) and glucocorticoids are commonly used antiinflammatory drugs. They act by inhibiting cyclooxygense enzyme. Newer NSAIDS are selective for COX 2. Drugs belong to this group selectively block COX-2 activity more than COX-1 activity, thus interfering less with protective action of CoX-1 in the stomach, blood vessels and, kidneys. ${ }^{6}$

\section{METHODS}

\section{Plant material}

The rhizomes of Curcuma longa were collected locally and pharmacognostically identified before use. Its botanical identity was confirmed and certified by the Pharmacognosy unit, Ayurvedic Research Institute (A.R.I), Poojappura, Thiruvananthapuram.

\section{Preparation of extract}

The rhizomes were washed with water, air-dried and cut into small pieces. The extract was prepared by soxlet extraction with $50 \%$ ethanol. The percentage yield was 4.9

\section{Animals used}

Albino rats of Wistar strain (170-250 grams) obtained from the animal house of medical college Thiruvananthapuram were used. They were fed a standard diet and maintained under standard laboratory conditions.

\section{Drugs}

Aspirin was purchased from Sigma Labs, Mumbai.

\section{Carrageenin induced paw oedema}

Anti-inflammatory activity of the extract was studied by the method described by winter et al where rat paw oedema was induced using carrageenin and the oedema measured using the modified plethysmometer. ${ }^{7}$ Albino rats of both sexes weighing 120-160grams were used for the study. They were randomized into 5 groups of 6 animals each. They were deprived of food overnight but allowed free access to water. Next morning the rats were administered the following drugs orally.

- Group I (control): 1\% CMC (Carboxy Methyl Cellulose) (1 ml/100gram body weight).

- Group II (standard): Acetyl Salicylic Acid in a dose of $300 \mathrm{mg} / \mathrm{kg}$ body weight suspended in $1 \% \mathrm{CMC}^{8}$

- Group III (test group 1): Ethanolic extract of Curcuma longa in a dose of $250 \mathrm{mg} / \mathrm{kg}$ body weight suspended in $1 \%$ CMC.

- Group IV (test group 2): Ethanolic extract of Curcuma longa in a dose of $500 \mathrm{mg} / \mathrm{kg}$ body weight suspended in $1 \% \mathrm{CMC}$.

- $\quad$ Group V(test group 3): Ethanolic extract of Curcuma longa in a dose of $1000 \mathrm{mg} / \mathrm{kg}$ body weight suspended in $1 \% \mathrm{CMC}$.

After 1 hour of drug administration, $0.1 \mathrm{ml}$ of $1 \%$ carrageenin suspended in sterile $0.9 \% \mathrm{NaCl}$ was injected through a $26 \mathrm{G}$ needle into the plantar tissue of the left hind paw. ${ }^{9}$ Immediately thereafter, the volume of the injected paw was measured using plethysmometer. ${ }^{10}$ This gave the initial paw volume (IPV). After 3 hours of carrageenin 
administration the paw volume was again measured to get the final paw volume (FPV). The percentage of inhibition was calculated by the formula. ${ }^{7}$

$$
\% \text { Inhibition }=\frac{(\mathrm{X}-\mathrm{Y})}{\mathrm{X}} \times 100
$$

$\mathrm{X}=$ mean difference in paw volume of rats in the control group $\mathrm{Y}=$ mean difference in paw volume of rats in the drug treated group.

Statistical analysis was done by one-way ANOVA (Analysis of variance) to compare the means in the experimental groups. Mean and standard deviation was found out. Duncans Multiple Range (DMR) test (Post Hoc analysis using DMR test) was done to find out the significance of various test results.

\section{RESULTS}

\section{Carrageenin induced paw oedema}

All doses of ethanolic extract of Curcuma longa inhibited the development of oedema at the end of 3 hours. The antiinflammatory activity exhibited by the extract was statistically significant at dose levels of $1000 \mathrm{mg} / \mathrm{kg}$ and comparable to that of standard drug used aspirin. At dose levels of $500 \mathrm{mg} / \mathrm{kg}$ and $250 \mathrm{mg} / \mathrm{kg}$ there was no significant action and is comparable to that of control. Aspirin produced $96.83 \%$ inhibition of oedema while the test drug produced $9.77 \%, 70.73 \%$ and $87.80 \%$ inhibition of oedema at doses 250, 500 and $1000 \mathrm{mg} / \mathrm{kg} \mathrm{b} / \mathrm{w}$ respectively.

Table 1: Effect of ethanolic extract of Curcuma longa on carrageenin induced rat paw oedema.

\begin{tabular}{|lllll|}
\hline Groups & Drug & Dose: $\mathbf{m g} / \mathbf{k g ~ b . w ~ o r a l l y ~}$ & $\begin{array}{l}\text { Volume difference in } \\
\text { ml (FPV-IPV) }\end{array}$ & $\begin{array}{l}\text { Inhibition of } \\
\text { oedema }(\%)\end{array}$ \\
\hline I & Vehicle (1\%CMC) & - & $0.41 \pm 0.06$ & - \\
\hline II & Acetyl salicylic acid & 300 & $0.01 \pm 0.01$ & 96.83 \\
\hline III & Extract of Curcuma longa & 250 & $0.37 \pm 0.01$ & 9.77 \\
\hline IV & Extract of Curcuma longa & 500 & $0.37 \pm 0.01$ & 70.73 \\
\hline V & Extract of Curcuma longa & 1000 & $0.05 \pm 0.06$ & 87.80 \\
\hline
\end{tabular}

$\mathrm{n}=6$; Values are expressed as mean \pm SEM; ${ }^{*} \mathrm{p}<0.05 ; * * \mathrm{p}<0.01 ; * * * \mathrm{p}<0.001$

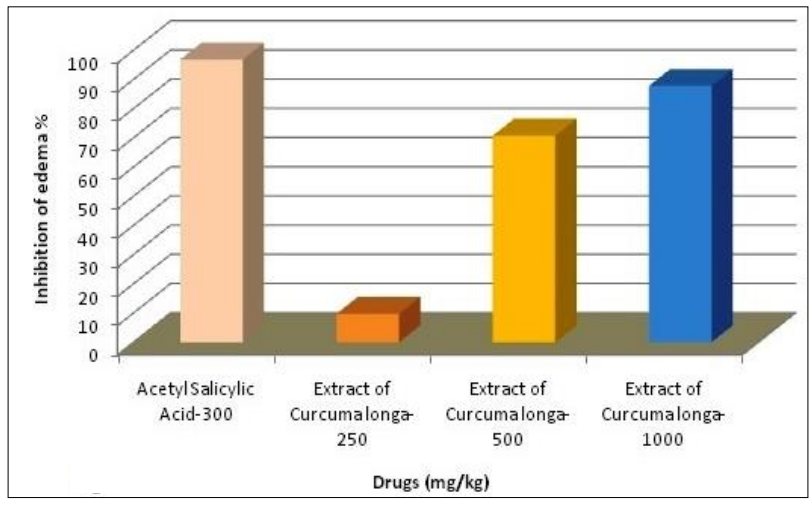

Figure 1: The effect of ethanolic extract of Curcuma longa and acetyl salicylic acid on carrageenin induced rat paw oedema.

Table 2: Analysis of variance for carrageenin induced rat paw oedema.

\begin{tabular}{|lll|}
\hline & Mean & $\begin{array}{l}\text { Standard } \\
\text { deviation }\end{array}$
\end{tabular} F-value

$\mathrm{n}=6 * \mathrm{p}<0.05 ; * * \mathrm{p}<0.01 ; * * * \mathrm{p}<0.001$
Table 3: Post Hoc Tests (analysis) - homogeneous subsets: Duncan's Multiple Range (DMR) Test for carrageenin induced rat paw oedema.

\begin{tabular}{|llc|}
\hline Groups & \multicolumn{2}{l|}{ Subset of alpha $=\mathbf{0 . 0 5}$} \\
\hline Standard & $\mathbf{1}$ & $\mathbf{2}$ \\
\hline Drug 1000 & 0.0133 & \\
\hline Drug 500 & 0.0500 & 0.3733 \\
\hline Drug 250 & 0.3733 & 0.3733 \\
\hline Control & 0.3733 & 0.4133 \\
\hline
\end{tabular}

Means for groups in homogeneous subset are displayed

Uses Harmonic Sample size $=6.000$

\section{DISCUSSION}

In the present study it is found that ethanolic extract of Curcuma longa in all doses inhibited the development of oedema at the end of 3 hours. There was significant anti inflammatory activity. The anti-inflammatory activity exhibited by the extract was statistically significant at dose levels of $1000 \mathrm{mg} / \mathrm{kg}$ and comparable to that of standard drug used aspirin. At dose levels of $500 \mathrm{mg} / \mathrm{kg}$ and $250 \mathrm{mg} / \mathrm{kg}$ there was no significant action and is comparable to that of control. Aspirin produced $96.83 \%$ inhibition of oedema while the test drug produced $9.77 \%$, 
$70.73 \%$ and $87.80 \%$ inhibition of oedema at doses 250,500 and $1000 \mathrm{mg} / \mathrm{kg} \mathrm{b} / \mathrm{w}$ respectively.

Curcuma longa has been used in traditional medicine for treating various diseases Extensive review regarding the protective and therapeutic uses of Curcumin by Sudhanshu Agarwal and co-workers elaborates its potential antiinflammatory actions. ${ }^{11}$ The present study supports the traditional use of this plant against inflammation. Curcuma longa showed significant inhibitory effects on acute inflammation. The development of carrageenin-induced oedema is a biphasic event. The initial phase is attributed to the release of histamine and serotonin $(5-\mathrm{HT})$ and the oedema maintained during the plateau phase by the kinin like substances. The second accelerating phase of swelling is related to the release of prostaglandin like substances. $^{12-14}$ Flavanoids and terpenoids are polar substances effective in acute inflammation whereas glycosides and steroids are non-polar substances effective in chronic inflammation. ${ }^{15}$ Further studies are necessary to detect the exact mode of action of Curcuma longa.

Curcumin the active ingredient in Curcuma longa, inhibit a number of different molecules involved in inflammation including phospholipase inducible tumor necrosis factors (TNF lipoxygenase, cyclooxygenase, leukotrienes, thromboxane, collagenase and elastase). ${ }^{2}$ Srivastava $\mathrm{R}$ and coworkers revealed the turmeric's potential for inhibiting platelet aggregation. ${ }^{15}$ The inhibition of platelet aggregation by Curcuma longa constituents is thought to be via its potentiation of prostacyclin synthesis and inhibition of thromboxane synthesis. These effects have been noted even with low doses of turmeric. ${ }^{16}$ In a study it was found that Curcumin, which is a polyphenol have been shown to suppress activation of NF-kappa B, which is involved in regulation of Cyclooxygenase-2 (COX-2) and nitric oxide synthase (iNOS) expression. COX-2 and iNOS are important enzymes that mediate inflammatory processes. Improper up-regulation of COX-2 and/or iNOS has been associated with pathophysiology of certain types of human cancers as well as inflammatory disorders, since inflammation is closely linked to tumor promotion. Curcumin inhibited the expression of COX-2 protein in a dose-related manner.

One of the possible mechanisms underlying inhibition of NF-kappa $B$ activation by curcumin may involve repression of degradation of the inhibitory unit I kappa B alpha, which hampers subsequent nuclear translocation of the functionally active subunit of NF-kappa B. ${ }^{17}$ In a study curcumin was shown to inhibit neutrofil aggregation associated with inflammation, in monkeys. ${ }^{18}$ Another in vitro study, demonstrated that low concentrations of curcumin incubated with activated macrophages resulted in a decrease in mRNA levels and nitric oxide synthase activity. This study demonstrates curcumins antioxidant role in down regulating nitric oxide formation, a key element in inflammation and possibly in the process of carcinogenesis. ${ }^{19}$ The effects of curcumin on 12-Otetradecanoylphorbol-13-acetate

(TPA)-induced expression of cyclooxygenase-2 (COX-2) in female mouse skin were studied by Chun KS and coworkers. ${ }^{20}$ Topical application of the dorsal skin of female mice with TPA led to maximal induction of cox-2 mRNA and protein expression. When applied topically onto shaven backs of mice prior to TPA, curcumin inhibited the expression of COX-2 protein in a dose-related manner. Immunohistochemical analysis of TPA-treated mouse skin revealed enhanced expression of COX-2 localized primarily in epidermal layer, which was markedly suppressed by curcumin pre-treatment. Curcumin treatment attenuated TPA- stimulated NF-kappaB activation in mouse skin. Taken together, suppression of COX-2 expression by inhibiting ERK activity and NFkappaB activation may contribute to the anti-inflammatory activity of curcumin. Potent anti oxidant action of Curcuma longa was which was demonstrated by an integrated metabolomic approach by authors may be also contributing to its anti-inflammatory action. ${ }^{21}$

The actions of anti-inflammatory drugs are predominately through inhibition of prostaglandin. Interestingly prostaglandins were found to be powerful inhibitors of gastric acid secretion and thus have a protective role against ulcer formation. Ulceration is seen in drugs, which inhibit cyclooxygenase and phospholipase like NSAIDs and steroids. COX 1 is a constitutive or housekeeping enzyme unlike COX 2, which is inducible. Inhibition of COX 1 has been attributed to inhibition of prostaglandin synthesis in the stomach and hence increased chances for gastric ulceration. Curcuma longa is found to have ulceroprotective action. ${ }^{22}$ So it can be assumed that there is not much inhibition of COX 1 . Anti inflammatory action with its ulceraoprotective property will be beneficial to the patients in long term management of inflammatory conditions and will be an added advantage over currently used anti-inflammatory drugs with many adverse effects including gastritis and peptic ulcer.

\section{CONCLUSION}

The present study with extract of Curcuma longa helped to find out some of its medicinal properties. The study revealed that it has significant anti-inflammatory properties. The results of the present study supports the previous studies conducted elsewhere that Curcuma longa has anti-inflammatory activity. Further studies are needed to find out the active ingredients and exact mechanism of action. It is a promising anti-inflammatory agent, since the available anti-inflammatory drugs such as corticosteroids and NSAID's have many adverse effects in therapeutic doses. Its ulceroprotective and antioxidant properties also may be beneficial in the management of chronic inflammatory conditions.

Funding: No funding sources

Conflict of interest: None declared

Ethical approval: The study was approved by the Institutional Ethics Committee 


\section{REFERENCES}

1. Ghatak N, Basu N. Anti-inflammatory activity of Curcumin and Sodium curcuminate. Indian J Exp Biol. 1972;10:235-6.

2. Chainami Wi N. Safety and anti-inflammatory activity of curcumin, a component of Turmeric. J Alter Complement Med. 2003;9(1):161-8.

3. Chensue SW, Ward PA. Inflammation. Ivan. Damjanov, James Linder. Editors. Anderson's Pathology. $10^{\text {th }}$ Ed. Mosby-year book, Inc; 1996;(1):387-410.

4. Mitchell RN, Cotran RS. Acute and chronic inflammation. In: Kumar V, Cotran RS, Robbins SL, editors. Basic Pathology. 6thed. Bangalore: Prism Books Pvt Ltd; 1997:25-46.

5. Rang HP, Dale MM, Ritter JM. Pharmacology. $4^{\text {th }}$ Ed. Edinburgh: Churchill Livingstone; 1999:215-216.

6. Roberts II LJ, Morrow JD. Analgesic- antipyretic and anti-inflammatory agents and drugs employed in treatment of gout. In: Hardman JG, Limbard LE, Gilman AG, editors. Goodman \& Gilman's. The Pharmacological Basis of Therapeutics. $10^{\text {th }}$ Ed. New York: McGraw-Hill; 2001:215-216.

7. Winter CA, Risley EA, Nuss GW. Carrageenin induced oedema in hind paw of the rat as an assay for anti-inflammatory drugs. Proc Soc Exp Boil Med 1962;111:544-7.

8. Chauhan O, Godhwani JL, Khanona NK, Pendse VK. Anti-inflammatory activity of Mukhashukti Bhasma. Indian J Exp Biol. 1998;(36):985-89.

9. Cashin $\mathrm{CH}$, Dawson $\mathrm{W}$, Kitchen EA. The pharmacology of Benoxaprofen (2-[4-chlorophenyl]$\alpha$-methyl-5-benzoxazole acetic acid), LRCL 3794, a new compound with anti-inflammatory activity apparently unrelated to inhibition of Prostaglandin synthesis. J Pharm Pharmacol. 1977;29:330-6.

10. Singh H, Ghosh MN. Modified Plethysmometer for measuring foot volume of unanaesthetised rats. J Pharm Pharmacol. 1968;20:316-7.

11. Agarwal S, Goel R. Curcumin and its protective and therapeutic uses. National Journal of Physiology, Pharmacy and Pharmacology. 2016;6(1):1-8.

12. Chauhan O, Godhwani. JL, Khanna. NK, Pendse VK. Anti-inflammatoy activity of Mukthashukti bhasma. Indian J Exp Biol. 1998;36:985-9.
13. Larsen GL, Henson PM. Mediators of inflammation. Ann Rev Immunol. 1983;1:335-59.

14. Brooks PM, Day RO. Nonsteroidal anti-inflammatory drugs: differences and similarities. $\mathrm{N}$ Engl J Med. 1991;324:1716-25.

15. Dahanukar SA, Kulkarni RA, Rege NN. Pharmacology of medicinal plants and natural products. Indian J Pharmacol. 2000;32:84-6.

16. Srivastava R, Puri V, Srimal RC, Dhawan BN. Effect of curcumin on platelet aggregation and vascular prostacyclin synthesis. Arzneim Forsch. 1986;36:7157.

17. Surh YJ, Chun KS, Cha HH, Han SS, Keum YS, Park $\mathrm{KK}$, et al. Molecular mechanisms underlying chemo preventive activities of anti-inflammatory phytochemicals: down-regulation of $\mathrm{COX}-2$ and iNOS through suppression of NF-kappa B activation. Mutat Res. 2001;480-1,243-68.

18. Srivastava R. Inhibition of neutrophil response by curcumin. Agents Actions. 1989;28;298-303.

19. Dixit M, Rastogi L, Shukla R, Srimal RC. Prevention of ischemia-induced biochemical changes by curcumin and quinidine in the cat heart. Indian $\mathrm{J}$ Med Res. 1995;101:31-5.

20. Chun KS, Keum YS, Han SS, Song YS, Kim SH, Surh YJ. Curcumin inhibits phorbol ester-induced expression of cyclooxygenase-2 in mouse skin through suppression of extracellular signal-regulated kinase. Carcinogenesis. 2003;24(9):1515-24.

21. Rafathullah S, Tariq M, Al-Yahya MA, Mossa JS, Ageel AM. Evaluation of Curcuma longa for gastric and duodenal ant-ulcer activity in rats. $J$ Ethanopharmacol 1990; 9(1):25-34.

22. Dall' Acqua S, Stocchero M, Scheavon M, Golob S, Uddin J, Voinovich D, et al. New findings on the in vivo antioxidant activities of Curcuma longa extract by an integrated(I)NMR and HPLC-MS metabolomic approach. Fitoterapia. 2016;109(3):125-31.

Cite this article as: Savaringal JP, Lally MS. Anti inflammatory effect of rhizome of Curcuma longa. Linn, in Albino rats by the method of Carrageenin induced paw oedema. Int $\mathrm{J}$ Basic Clin Pharmacol 2018;7:229-33. 